\title{
Child well-being in a rural context: Shifting to a social sustainability lens
}

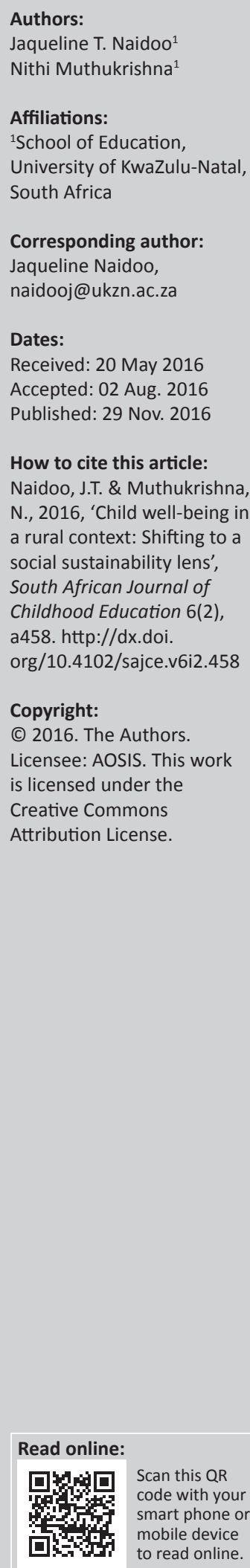

This article is based on findings drawn from a large-scale study aimed at mapping barriers to education in the context of social disadvantage. The research sites focused on in this paper are: one early childhood facility, four primary schools and the communities of these learning centres. Participants included learners, teachers, caregivers and parents and interested community members. Findings from the study were published widely in a research report, book chapters and peer-reviewed publications. In this article an attempt is made to revisit the findings on child well-being and quality of life, drawing on debates on sustainable development, in particular on the concept of social sustainability. The analysis draws attention to the importance of creating cultures of social sustainability within social institutions and communities to enhance the well-being of children. The article highlights the significance of values that are rights based and collective networks in cultures of sustainability.

\section{Introduction}

With the ratification of the UN Convention on the Rights of the Child (CRC) by most countries and the imperatives of the Millennium Development Goals (United Nations 1989, 2000), many of which are related to child health and well-being, research agendas on children exposed to adversity and their well-being have become a priority globally (Jones 2008; World Health Organization 2007; Wulczyn et al. 2010). Furthermore, this focus has been influenced by the recognition that children and youth, who often lack social power, are the most harshly affected by difficult circumstances such as HIV and/or AIDS, poverty, fragile families, crime, armed conflict, urbanisation, globalisation, exploitation and underdevelopment in communities and societies. There have been concerns internationally for the protection of children and for the advancement of their well-being (Kabiru, Izugbara \& Beguy 2013; Lippman, Moore \& McIntosh 2009; Stevens \& Hassett 2007). In a similar trend in South Africa, over the past two decades in particular, there has been growth in research on child mental health, well-being and quality of life (Haffejee 2006; Hall et al. 2012; Human Rights Watch 2001; Nelson Mandela Foundation 2005).

Much of this body of work highlights the major influences on the well-being of children located in sociopolitical and economic contexts. However, most of these research agendas fail to integrate social science disciplines to enable an in-depth understanding of the complexities of children's lives and their well-being, as argued by Kabiru et al. (2013). Many studies point to the indicators of child well-being, focusing largely on negative indicators and child ill-being with the aim of drawing attention to areas for social change. Lippman et al. (2009) stress the need for an equal focus on positive and negative indicators, for example vulnerabilities, resiliencies, risks, agency and coping. They also argue for the need to link indicators of child well-being to local contexts as such a focus may reflect a more positive representation of children and may better inform the goals societies and communities strive for to enhance child well-being.

In the context of the above debates, this article interrogates findings from a case study research project conducted in a rural context in South Africa. The study aimed at mapping barriers to education in the context of social disadvantage. The findings of this study have been widely published in peer-reviewed journals and book chapters. In this article these findings are further interrogated to explore new meanings using the notion of social sustainability as a conceptual framework. The question put forth is: What sustainability aspects protect or impede the health and well-being of young children in the study context? How can the well-being of young children be enhanced in contexts of social disadvantage? 


\section{The notion of social sustainability in the context of child well-being}

In this section, the concepts 'child well-being' and 'social sustainability' are examined as they are framing concepts for this article. The conceptualisation of well-being has been the subject of academic and policy debates internationally (Boyden \& Mann 2005; Bradshaw, Hoelscher \& Richardson 2006; Earls \& Carlson 2001). Despite the global use of the concept 'well-being', literature depicting systematic analyses of the concept tends to emanate from countries of the north, and reflects numerous ways of understanding and determining the well-being of children. There is also a focus on examining the factors that produce well-being, and the links between various facets of child well-being. How well-being is conceptualised depends on the frameworks that are used.

Hanafin and Brooks (2005) point out that the diverse frameworks reflect differences in the embedded beliefs about children. The child development approach tends to examine and focus on deficits with the view that such an approach would help address social inequalities and the marginalisation of children, generally neglecting the potential and strengths of children. A counter paradigm referred to as the sociology of childhood or new childhood studies proposed in the 1990s by leading scholars, such as Prout and James (1990), James, Jenks and Prout (1998) and Mayall (2002), focuses on children as social actors with competence, agency and resilience. From this conceptualisation, children are seen as active in the construction of their own social lives. The need for researchers to create spaces for the participation of children in research and to allow their voices to be heard is foregrounded. From this paradigm, childhood is viewed as a social construction, and therefore, children and their unique social realities and cultures are worthy of study in its own right.

On the other hand, from a social rights perspective, constructions, indicators and gauges of well-being highlight enabling factors and processes that support children to reach their full potential (Statham \& Chase 2010). The UN CRC (United Nations 1989) provides a normative framework for making sense of children's well-being. Its four general principles are: non-discrimination, best interests of the child, survival and development, and respect. Internationally, these have been central to debates on how to conceptualise child well-being. Respect for the child foregrounds the right of the child to be listened to and to have their views heard on issues that affect their lives.

On another dimension, a risk and resilience perspective presents a dynamic and transactional conceptualisation of child well-being (Hanewald 2011; Jensen \& Fraser 2005). Child outcomes are viewed as not static as influences on their lives are constantly changing and children's capacities evolve over time and differing situations. Children also create their well-being. Well-being is seen as a dynamic state. Thus, an important argument from the risk and resiliency perspective is children are able to play an active role in producing, crafting and mediating their own well-being. Furthermore, central to resilience is the presence of personal agency in children rather than just an absence of pathology (Jensen \& Fraser 2005). The thinking is that children's own ingenuity and agency may foster and shape their well-being. In other words, there is a shift from the notion of protective factors to a perspective that children can actively negotiate and navigate their lives.

An analysis of literature in the last decade suggests that, although a contested concept, many conceptualisations of child well-being foreground that it is multidimensional and ecological, and must take into consideration the complexity of children's lives, contexts and relationships (Boyden \& Mann 2005; Bradshaw et al. 2006; USAID 2011). Furthermore, child well-being interventions should include contextual dimensions of physical, emotional and social well-being, and should focus not merely on the current lives of children but should also place under the lens their future lives. These debates argue for the need to incorporate subjective as well as objective measures. Objective measures include household income, educational resources and health profile, and subjective indicators include happiness, feelings of safety and security, experience of a sense of dignity and a sense of mastery in particular settings (e.g. schooling) and life satisfaction (Statham \& Chase 2010). Well-being thus is about the state of being or functioning well in life, life satisfaction, being healthy; the focus is on the child as a whole.

In this article an attempt is made to link debates on child well-being to those that focus on the concepts of sustainability and sustainable development. Sustainability is viewed as the goal or culmination of a process referred to as 'sustainable development'. The majority of scholars agree that sustainable development promotes environmental, economic and social well-being for present as well as future generations (Diesendorf 2000; Murphy 2012). Furthermore, the view is that sustainable development is context dependent. The process includes the form of economic and social development which safeguards, builds and enhances the natural environment and promotes social equity (Diesendorf 2000). Diesendorf (2000) asserts that the economic and social aspects of sustainability are conceptualised as a single concept, 'human sustainability'. Thus, the concept of sustainability can refer to both the planet and to human society. If one applies the concept to social institutions, one can consider the degree to which they are 'sustainability-promoting' or 'sustainability-impeding' (Diesendorf 2000:21).

However, the social well-being pillar of sustainability, referred to as social sustainability, has been marginalised in debates. According to Woodcraft (2012), it is a fluid concept and is under-theorised and poorly defined in policy discourse or practice. Weingaertner and Moberg (2011) and Woodcraft (2011) draw attention to the challenges of operationalising 
social sustainability for purposes of social intervention. In this article we draw on the recent debates of scholars who have attempted to address the confusion in the definition of social sustainability and highlight key aspects of social sustainability. Ghahramanpouri, Lamit and Sedaghatnia (2013:189) through their review of literature delineate certain key aspects of social sustainability, which include 'social equity (equal access to services, facilities and opportunities), satisfaction of human need, well-being, quality of life, social interaction, cohesion and inclusion, and a sense of community'.

Other scholars emphasise human well-being to suggest that some components of social well-being are sufficient food, good dwellings, personal security in terms of both physical and emotional dimensions, access to learning opportunities, opportunities for social interaction, a network of support to enhance the emotional dimension, opportunities for creative behaviour and a social context that respects human rights and does not foster a sense of alienation and exclusion (Leslie 2009; Greenstreet 2011; Weingaertner \& Moberg 2011). While these aspects may be dependent on economic conditions, they are shaped to a large extent by social structure, social mechanisms and social institutions.

To summarise, the key issues of interest for social sustainability may include: a sense of belonging and support, access (e.g. access to quality education and training, employment, social services and resources), health and well-being, safety and security, social capital and social networks, social cohesion, social inclusion and respect for the rights of different cultures, traditions and backgrounds, equitable distribution of income, employment opportunities, democracy and participation at local level. In general, there is a common perspective that social sustainability is about fostering, uplifting or maintaining the quality of life of people, including children, in a community and in society. Both the individual and collective are critical to social sustainability.

In the next section, the findings from the 'mapping barriers to learning' project, an in-depth qualitative case study (Muthukrishna 2006), are revisited from the perspective of child well-being. In the final discussion section of the article, the findings are examined through the lens of social sustainability.

\section{Methodology \\ Study context and participants}

The study was undertaken in a rural context in the province of KwaZulu-Natal. Sampling was purposive. The research site, a small town and its surrounding areas, was selected for its unique social, political, economic and community history. The town is surrounded by agricultural farmlands with largely a migrant labour force and has a population of approximately 70000 people living in semiformal and informal settlements. The town experienced intense political violence during the apartheid era. The aftermath of this particular history was high unemployment, poverty and antisocial behaviours such as substance abuse, unsafe sexual practices and crime. Although a process of peace and reconstruction had been underway at the time of the study, the high population mobility, high unemployment rates and the continued social fragmentation have resulted in high rates of HIV and/or AIDS infections (Killian et al. 2008).

This article discusses findings from one rural early childhood centre and four rural primary schools and their communities. Sampling was purposive in that the focus was on the rural early childhood centres of learning which were part of the larger study. Participants included learners, teachers, caregivers and parents. An innovative aspect of the study was that researchers were committed to giving voice to children through participatory data generation tools. Influenced by debates that have emanated from the sociology of childhood (James et al. 1998; Mayall 2002; Prout \& James 1990), researchers held the view that children are competent beings and active in the construction of their own social realities and those spaces for the participation of children in research must be created.

\section{Data generation}

Data generation methods were semi-structured individual interviews and focus group interviews. A participatory approach to data production was followed to enable the production of knowledge in an active partnership with the participants (Babbie 2002). The aim of a participatory approach is to address inherent power imbalances between the researcher and the participants in often marginalised communities. Some of the creative, participatory techniques included social mapping, body mapping, ranking exercises, photo-voice and children's drawings (see Muthukrishna 2006). The interviews were conducted in either isiZulu or English to ensure access to all participants. The interviews were audio- and/or video-recorded, later transcribed and translated from isiZulu into English, where necessary.

In the study, a challenge was that original interviews and focus group discussions were done in isiZulu, and the medium of communication within the research team was English. The process was without doubt complex as selected researchers, many of whom were postgraduate students, conducted the interviews and focus groups in isiZulu and then had to translate the data into English for the larger research team. Translation is a complex task and one cannot assume that there is expertise in this skill because an individual can speak two languages. Thus, there was much debate among researchers about finding the appropriate isiZulu equivalent to English words and concepts and vice versa.

\section{Ethical considerations}

A key ethical issue in the project was upholding respect for all participants. As the research involved entering into the 
private spaces of participants, it had to be particularly responsive to issues of confidentiality and anonymity. Issues of informed consent, confidentiality, anonymity and voluntarism were engaged with in every phase of the project with all participants.

The team of researchers was very cognisant of the complexities of doing research with child participants that is authentic, respects their views and integrity, addresses the power imbalances that exist between adults and children, and is non-exploitative. We were also aware that we were doing research in a sociocultural and historical context in which children's voices are seldom heard or listened to. For this reason, we adopted a reflexive stance as researchers throughout the research process that informed the development of child-friendly participatory research tools to maximise the participation of the children. As a team we committed to doing research with the children rather than on them. Van der Riet, Hough and Killian (2005) provide a critical account of the methodological and ethical challenges to child participation in the project.

All participants signed informed consent forms either in English or isiZulu. Learners selected their own code names as pseudonyms within the focus group interviews. Learners were also given confidentiality pledges to sign (see Van der Riet et al. 2005), and through this process individual confidentiality was concretely displayed to the children. Permission was initially obtained from the provincial Department of Education and the mayor of the town. Furthermore, ethical clearance was obtained through the Research Office, University of KwaZulu-Natal.

\section{Data analysis}

Through a case study approach, it was possible to triangulate the multiple facets of data obtained from the various participants and schooling settings through the various collection techniques. The data analysis process involved the coding and relating of concepts that emerged in the data. In the first step, recurring topics that emerged within and across the different data sets were identified. The topics were further scrutinised to isolate categories of meaning. The next step involved distinguishing patterns of relationships among categories. This process of pattern seeking involved searching for and making sense of the complex linkages between situations, beliefs, values, experiences, perspectives and actions. Generating patterns in the data meant seeking out recurring ideas, concepts, issues, perspectives and descriptions that represented the social reality (see Muthukrishna 2006). A data-driven and theory-driven process occurred. The qualitative data analysis software programme, NVIVO, was used to organise the data.

\section{Findings of the study}

The key findings documented in various peer-reviewed publications will be presented and critiqued to raise new questions and issues related to child well-being. The study revealed that childhood is a varied, fluid category shaped by sociocultural contexts. The analysis of published findings show that risk and resilience literature informed arguments and conceptualisations of child well-being in the research context (Govender \& Ebrahim 2008; Jacobs \& Harley 2008; Killian et al. 2008; Muthukrishna 2006; Muthukrishna \& Ramsuran 2007; Muthukrishna et al. 2007). The study revealed numerous processes and factors at the individual, family and social context levels that significantly impact the well-being of children.

\section{Risks in children's lives}

Fraser and Terzian (2005) broadly define a risk factor as any happening, state, circumstance or experience that intensifies the chances of a child suffering a specific adverse situation or negative outcome. Daniel (2010) further elaborates that risk factors can increase the probability of an adverse experience having a significant negative impact upon wellbeing during childhood.

The study found that children in the research context face a multitude of risks and vulnerabilities, including being affected by HIV and/or AIDS, crime, substance abuse, poor health and safety in schools, corporal punishment, unequal access to education and healthcare, poverty and underdevelopment and exposure to social risks such as abuse of a physical or sexual nature (see Govender \& Ebrahim 2008; Jacobs \& Harley 2008; Killian et al. 2008; Muthukrishna 2006; Muthukrishna \& Ramsuran 2007; Muthukrishna et al. 2007). This is illustrated in the narratives below:

'Children get raped. We heard there is a car that took children and raped them. So far nothing has happened. We have not seen anything. But we try to protect our children. We are forced to accompany them to school and fetch them after school. We have to watch our children. They have to play in front of us - cannot be out of sight.' (Mother of preschool child)

A serious violation of the rights of learners is the inability of government and communities to provide basic services such as food, shelter and welfare services for the growing number of AIDS-related orphans:

'I was having a child who was crying everyday, everyday reporting this and that. When parents died then he was living with the auntie. And the auntie said you don't touch this food, it's for my kids. So, it's all those things.' (Teacher)

The emotional distress of living in the context of the HIV/ AIDS pandemic was seen in children's fear of their own, or of a loved one's death and sickness. For example, when asked: 'What do you like about your life? What would you change about your life?' What do you like about yourself? A Grade 3 learner responded:

'I am happy that both my parents are still alive. I wish no one would die at home. I glad I am still alive.' (FG3, Grade 3)

These risks are contextual in nature, emanating either from their own lives, immediate family, community or wider social contexts. The risks present a direct challenge to children in 
the study context. Jacobs and Harley (2008) highlight the issue of the many fragile families that appear to be constantly under strain. The majority of the households they examined seemed to be disjointed and fractured, with one or both parents dead or missing. There were also high levels of what the researchers term 'child mobility' in the context of the HIV and AIDS pandemic where children were moved from one home to another depending on current circumstances and on who was prepared to care for them. In many homes, the grandmother was found to be the primary caregiver. The study found that poverty was the most insidious and pervasive barrier to children's social wellbeing and development. Muthukrishna and Ramsuran (2007:411) explain that 'poverty seems to be part of a web of human rights violations that children and their families experience'. The study showed that risk and vulnerability is shaped, entrenched and sustained by social and structural processes in the community and society, for example barriers to families accessing social redistribution instruments such as the Child Support Grant.

Internationally, it is conceded that a school has a moral and legal function to contribute to children's well-being and sound, healthy development. This is an important facet of the whole pedagogical enterprise as a child's well-being is critical to curriculum access. A key task of a teacher is building competence in children and enhancing well-being to achieve positive learning and development outcomes. The study revealed that in many schools the well-being of children is placed at risk in schooling contexts. The narratives below highlight instances of violation of children's right to protection and right to basic education entrenched in the South African legislation such as the South African Schools Act of 1996 and the Children's Act of 1995. In many rural contexts, teachers as a social group are in positions of power and are often viewed as high in social status compared to learners, their families and communities. The teacher in the excerpt below explains how the school reports of students are withheld and released only on payment of school fees. This is in violation the South African Schools Act of 1996:

'We are doing what we are not supposed to do. We hold their results at the end of the year and they (parents/caregivers) come in numbers, then they will pay and we release the reports. Even the parent pays in the following year. Now we are in 2005, the parent will pay in 2006 January. You know in order to see the class position of the child.' (Teacher)

The study also indicated that some teachers choose not to act when faced with complex ethical issues, and in this way add to the vulnerability of children. For example in the following excerpt a teacher recounts how the school had not acted in a case of alleged child sexual abuse:

Teacher: Like I got these two girls in my Grade 2 class. They are being raped by their relatives. One is the mother's boyfriend and the other is the uncle.

Researcher: Does the school have a support system for children? Who do they talk to?
Researcher: What is being done by the school?

Teacher: Not yet. Nothing is happening.

Ramsuran and Lurwenga (2008) argue that often the view of school as a 'safe space' is disrupted by the conduct of the very people who are the guardians of learners' safety and wellbeing. However, one has to be cautious against taking such a critical stance, especially regarding teachers' pastoral role or lack of it. The study also found instances of authentic caring and support towards children which will be highlighted in the next sub-section.

The study suggests that it is important for administrators, school leaders, teachers and others in educational communities to recognise the sometimes hidden or taken for granted values that guide their actions and the action of others, and that these may have a detrimental impact on children's well-being.

\section{Resiliency and protective factors that mediate in children's lives}

Protective processes are individual or contextual mechanisms that enhance resiliency through alleviating the negative impact of risk factors (Hanewald 2011). These may include strong family connectedness at the micro-system level. At the mesosystem level, it may include access to educational resources and facilities. Finally, at the macro-level it would include sound protective policies and beliefs, values and practices that aim to protect children, decrease vulnerability and marshal protective mechanisms and processes. Hanewald (2011) argues that protective factors offset risk factors and are located in three key systems in the child's life: family, school and community.

In the study, alongside complex risk factors embedded in schooling contexts, family and community children's narratives revealed protective and resiliency enhancing factors. This shows that the school community can play a critical role in enhancing children's well-being. In the family, children spoke of the importance of warmth and support. The presence of external support systems that build, shape and reinforce children's coping efforts did emerge in the findings, for example attentive friends in school, caring teachers and family members.

The study indicated that teachers in the schools enacted various kinds of care work outside the formal curriculum. Complex demands are made on them from learners, parents and the school communities related to issues of violence, abuse, poverty, orphanhood, teenage pregnancy, child abuse etc. for which most teachers have had limited professional development. Muthukrishna and Ramsuran (2007) argue that this form of care work, illustrated in the data below, is often invisible and goes unrecognised:

'I can make one example, we have a problem that sometimes during break time or when we are having chips, this and that, they have this habit of asking for money. And to us we are not used to that they ask for money because they are hungry, and we give it to them because we feel guilty.' (Teacher) 
'There is a high rate of unemployment ... yesterday I made calculations and noticed that $8 \%$ of my salary is going to the learners that come every day asking for money. It has become strained ... and the department must do something about this.' (Teacher)

In a Grade 6 focus group, learners commented on caring relationships and supportive communicative spaces in the school context. For example:

'When I am walking with my friends to school, they make me forget things happening at home. If it is time to go back home I remember all the bad things that have been done to me.' (Learner, Grade 6)

The study showed that friendships create opportunities for children to be themselves, to feel good about who they are and to gain social and emotional competence. These processes build resilience and enhance well-being.

The study indicated that children do have a sense of enjoyment of aspects of their lives such as going to church and engaging in recreational activities. They are also able to engage in critical thinking about events and issues in their lives, they are able to articulate a sense of purpose, a belief in a positive future and a developing sense of morality and spirituality. Research suggests that these have a significant impact on resilience (Bradshaw et al. 2006; Fraser \& Terzian 2005).

Scholars argue that these protective factors have the potential to shape the strategies that children use to deal with traumatic situations and to shield themselves from distressing experiences and damage to their esteem (Boyden \& Mann 2005; Jones 2008). Other protective factors that emerged are a sense of curiosity, the need to help others; a life goal for which to strive and resourcefulness. Research has shown that children who are able to stay positive and optimistic about the future, those who have views and make meanings about their lives and assume some degree of control may be less vulnerable (Kabiru et al. 2013). The following excerpts give some insight into children as social actors who have a degree of self-efficacy and competency, and are able to actively make meanings of their lives:

'I like to have security at school because the community comes here if there is no one here and steals the school food and school soccer kits.' (Learner, grade 6)

Even Grade 3 children readily stated that using a condom prevented HIV infection and some of them demonstrated a fairly advanced understanding of the virus:

'If you have TB it's easy to get HIV because HIV eats your white blood cells that would have protected you from TB, and you end up thin like a mosquito.' (School B, Grade 3)

There is a high prevalence of migrant labour in the study context and children are often cared for by other family members, often grandmothers. Parents are often away from children for protracted periods. To the children, happy times are when parents are at home, gifts of food, celebratory occasions and unveiling rituals:
'It is the time when my mother comes back ... when she comes home there are nice things at home, and I feel comfortable to stay with my mother.'

'I am happy when they do a birthday for me.'

'I was happy at Christmas because we eat nice things that we don't eat every day.'

(Learners, focus group, grade 6)

Killian et al. (2008) point out that the data suggest that children in the study context lose agentive ability in the face of the degree of adversity to which they are exposed. However, review of the data sets show that there are informal social support systems that can be strengthened and enhanced in the communities to ensure greater cohesion. Particular community factors seem to play out as protective factors. Relatives and neighbours remain significant mitigating factors - many of the households would not survive without their intervention and support. The local community crèche and day care centre is seen by mothers as a safe haven for their children, and it plays a role in alleviating hunger and addressing inadequate nutrition in families. One mother voiced her views:

'We do like the crèche because young children get food at the crèche. Other children often do not get good food in the morning if they are not going to crèche. We like the teachers because they take care of our children.' (mother, focus group)

A mother explained that food parcels and other support from a Day Care and Support Centre in one of the communities are critical to the survival of families. However, Jacobs and Harley (2008) assert that households are less likely to receive support and assistance from neighbours and relatives if they too are under stress.

\section{Revisiting the findings: A social sustainability lens}

The argument in this article is that a social sustainability lens provides a framework for researching issues of child protection, resiliency and risk in children's lives. In this debate, the focus shifts to situated and contextual influences on children's lives. In this section of the article the aim is to show how two principles in the social sustainability viewpoint can be applied to inform the creation of sustainable rural ecologies that would protect children, reduce risks and build resiliency.

\section{Interrogating the values embedded in social institutions}

The study discussed above has shown that vulnerability, risk, resilience and coping are not merely functions of adversity in contexts but more importantly of beliefs and values that underpin social institutions. Neglect of children in the family and community, discrimination and marginalisation in schools; inequities that go unaddressed by schools, national and provincial governments are societal factors that undermine children's well-being, and point to the fact that children of certain social groups are not valued. 
The study showed that child well-being is contingent upon, and vulnerable to the beliefs, values and actions of other individuals in their social environments. This emphasises the contextual nature of risk and adversity. Thus, it is critical that the values embedded in social institutions such as a school are subjected to critique, scrutiny and analysis. According to Statham and Chase (2010), from a rights perspective, wellbeing of children is about the enabling influences, factors and processes in society that support children to reach their full potential emotionally, socially and academically. Values are crucially important in shaping children's experiences of adversity, and yet this issue has been neglected in the research. In this article we argue that how children experience adversity cannot be fully grasped without a focus on the sociocultural, economic, political and moral meanings embedded in such experiences. Why adults in children's worlds act or do not act in the face of child vulnerability is a question related to the values adults hold about children and childhood in contexts of social disadvantage and underdevelopment. Boyden and Mann (2005) point out that impact of adversity on children is determined not just by the objective nature of situations but children's subjective experiences of those situations. The question to ask is: What moral meanings or values do adults in social institutions and in communities hold about childhood as a social category, about poor children, rural children, disabled children and children of other social categories?

Scholars in the field of childhood studies have shown that adult definitions and assumptions of children and of childhood produce differences in terms of attitudes and behaviours towards children. In recent debates from the sociology of childhood, children are seen as active agents who can actively control and effect change in their lives (Prout \& James 1990). These debates have important implications for social policy at all levels, including at the level of the school and community. The study presented in this article revealed that the children are socially competent, have definite views and are capable of critical thinking about events in their lives that are good and bad for them. Yet, the data suggest that there are no spaces for their voices to be heard. Research has shown that socially competent children can build their resiliency by finding alternatives to their current circumstances and engaging with adults towards creative solutions (Lippman et al. 2009; Stevens \& Hassett 2007; Zolkoski \& Bullock 2012). Furthermore, children who have had experiences of affirmation, respect and spaces for success are more likely to be resilient than those who have been exposed to constant failure experiences, criticism, humiliation, exclusion and rejection. The sustained presence of at least one supportive adult in a child's life can have a significant impact on their resilience. Adults can serve as models of problem-solving, motivation and coping skills. Spaces and places need to be created within communities to build these resilience-promoting processes and relationships.

Earls and Carlson (2001) point to conceptualisations of wellbeing that have drawn on the capability approach of Amartya
Sen, the Nobel Laureate in Economics. Well-being is examined in terms of the capability to achieve valued functionings, required resources and opportunities to enact agency. Functionings would refer to the 'doings' and 'beings' of children as they try to lead their lives as human beings and would include having adequate nutrition, good health, access to quality education, being affirmed, achieving selfrespect or being socially included (Earls \& Carlson 2001). In a community seeking social sustainability, these valued functionings will be the focus of social intervention.

\section{Community networks and systemic support building}

Boydon and Mann (2005) contend that resilience is contingent upon both individual and group strengths and is shaped by enabling structures and systems in the wider community. In South Africa, as in many other countries of the south because of inadequate government intervention, child protection has become the responsibility of civil society. The structures may be formal (e.g. faith-based and non-governmental organisations) or they may be informal networks. Neighbourhoods and social institutions such as schools can help enhance protective factors at the level of the individual child and the family to build environments that sustain children's well-being. Thus, child well-being is determined by the quality of transactions between children and members of the community, including teachers, neighbours, parents and peers. In other words, child resilience is dependent upon both individual and group strengths. It is significantly shaped by supportive networks and protective processes in the wider environment.

Studies have shown that strong social support networks provided by relatives, community members, nongovernmental organisations and social service agencies, for example, are critical to mitigating adverse influences in children's lives. Communities need to create a space for engagement and collective responsibility for building sustainable childhoods (Boydon \& Mann 2005). Willms (2002) asserts that just as risk factors are cumulative, in the same way protective factors can have a cumulative effect on children's lives. Thus, the more protective influences present in a child's life, the greater the likelihood that the child will be resilient.

Yates and Masten (2004) argue for intervention programmes that are contextual and multi-systemic targeting the child, family and community levels. As evident in our case study, children's well-being is contingent upon other individuals and other settings of influence such as their family, school, community and cultural norms and values (Yates \& Masten 2004). The study reported in this article highlights the fragility of families and the issue of 'child mobility' in the face of the HIV and/or AIDS pandemic. The degree of resilience is determined by whether or not the child has a safe, protective base which gives them a sense of belonging.

Hanewald (2011) highlights three approaches to enhancing resilience in communities: risk-focused methods, 
asset-focused approaches and process-focused approaches. The aim of risk-focused methods is to decrease or prevent risks in an ongoing way (e.g. poverty alleviation interventions; access to community-focused programmes that help children and teachers deal with death, sickness and grief). The assetfocused approach emphasises resources that enable adaptive functioning to counteract adversity (such as access to healthcare; access to quality education). Hanewald (2011) explains that process-focused approaches aim to protect, build or restore community systems to support child wellbeing (i.e. strengthening informal support systems in communities). In the study context, all three approaches are evident; however, there is need for community-based, local interventions to strengthen and nurture them and further enhance support networks for children. A question to engage with is: How can we use current research to build and inform the creation of a social web of collective awareness and collective action to protect children and enhance resilience?

\section{Conclusion}

This article makes a contribution to wellness discourses related to education in rural contexts, a focus in research that is largely neglected in South Africa, according to Nkambule et al. (2011). The article highlights the importance of a culture in social institutions that is values-driven and where responses to child well-being are systemic and contextual in nature and build community networks of support.

An issue that is silent in debates is the values embedded in social institutions that impact children's lives, for example schools. Questions to be interrogated are: Do adults in children's lives place a high priority on the social rights and well-being of the child? Are children valued as social agents in communities and society? How much do adults know about children's own understandings of how they actively contribute to their own well-being, coping and survival? Do children have a space to play in their own protection?

Castillo et al. (2007:41) consider the issue of values when they declare that 'social sustainability can be defined as ensuring the well-being of current and future generations, by recognising every person's right to belong to and participate as a valued member of his or her community'. Leslie (2009) argues that in cultures of sustainability, values underpin, maintain and support attitudes and behaviours, and need to be scrutinised as a source for change. Examining values is a critical opportunity to bring about lasting sustainable change (Greenstreet 2011). This applies most significantly to interventions within communities that aim to enhance the well-being of children.

This study draws attention to the need for future research to focus on the importance of human agency in the creation of sustainable social organisations that are critical to the protection of the well-being of children and mitigating adversity. Research can provide insight into the elements of facilitating sustainable social environments and structures, and supportive values, attitudes and relationships that protect children's health, resilience and well-being and mediate risk. More data is needed in diverse contexts that can illuminate the structural forces and mechanisms that mediate the well-being of groups or different categories of children in varied ecological contexts, including isolated rural contexts. Such insights can be invaluable in informing a vision, ethical principles, goals, measurable objectives and action plans for contextually relevant intervention frameworks and programmes that aim to reduce risks in children's lives and build social sustainability.

\section{Acknowledgements Competing interests}

The authors declare that they have no financial or personal relationships which may have inappropriately influenced them in writing this article.

\section{Authors' contributions}

N.M. was the project leader. J.N. and N.M. were responsible for project design, data collection and conceptual contribution.

\section{References}

Babbie, E., 2002, The basics of social research, 2nd edn., Wadsworth, Belmont, CA.

Boyden, J. \& Mann, G., 2005, 'Children's risk, resilience, and coping in extreme situations', in M. Ungar (ed.), Handbook for working with children and youth: Pathways to resilience across cultures and contexts, pp. 2-26, Sage, Thousand Oaks, CA.

Bradshaw, J., Hoelscher, P. \& Richardson, D., 2006, 'An index of child well-being in the European Union', Social Indicators Research, viewed 4 April 2013, from http:// eprints.whiterose.ac.uk/1948/1/childEU.pdf

Castillo, H., Price, A., Moobela, C. \& Mathur, V., 2007, 'Assessing urban social sustainability: Current capabilities and opportunities for future research', The International Journal of Environmental, Cultural, Economic and Social International Journal of Environmental, Cultural, Economic and Social
Sustainability 3(3), 39-48. http://dx.doi.org/10.18848/1832-2077/CGP/v03i03/ 54355

Daniel, B., 2010, 'Concepts of adversity, risk, vulnerability and resilience: A discussion in the context of the "child protection system"', Social Policy \& Society 9(2), 231-241. http://dx.doi.org/10.1017/S1474746409990364

Diesendorf, M., 2000, 'Sustainability and sustainable development', in D. Dunphy, J. Benveniste, A. Griffiths \& P. Sutton (eds.), Sustainability: The corporate challenge of the 21st century, pp. 19-37, Allen \& Unwin, Sydney.

Earls, F. \& Carlson, M., 2001, 'The social ecology of child health and well-being', Annual Review Public Health 22, 143-166. http://dx.doi.org/10.1146/annurev. publhealth.22.1.143

Fraser, M.W. \& Terzian, M.A., 2005, 'Risk and resilience in child development: Practice principles and strategies', in G.P. Mallon \& P. McCartt Hess (eds.), Handbook of children, youth, and family services: Practice, policies, and programs, pp. 55-71, Columbia University Press, New York.

Ghahramanpouri, A., Lamit, H. \& Sedaghatnia, S., 2013, 'Urban social sustainability trends in research literature', Asian Social Science 9(4), 185-193. http://dx.doi. org/10.5539/ass.v9n4p185

Govender, K. \& Ebrahim, H., 2008, 'Listening to the voices of children in early schooling in the South African context of HIV/AIDS', Journal of Psychology in Africa 18(3), 485-488.

Greenstreet, T., 2011, 'Developing cultures of sustainability: Innovative ways of engaging creativity and values', Business Leadership Review 8(6), 1-10.

Haffejee, S., 2006, Waiting opportunities: Adolescent girls experiences of genderbased violence at schools, Centre for the Study of Violence and Reconciliation, Johannesburg.

Hall, K., Woolard, I., Lake, L. \& Smith, C., 2012, South African Child Gauge 2012, Children's Institute, Cape Town.

Hanafin, S. \& Brooks, A.M., 2005, Report on the development of a national set of child well-being indicators in Ireland, The National Children's Office, Dublin, viewed 06 November 2011, from http://www.nco.ie

Hanewald, R., 2011, Reviewing the literature on "at-risk" and resilient children and young people, viewed 10 August 2012, from http://ro.ecu.edu.au/ajte/vol36/ iss $2 / 2$

Human Rights Watch, 2001, Scared at school: Sexual violence against girls in South African schools, Human Rights Watch, Johannesburg. 
Jacobs, S. \& Harley, A., 2008, 'Finding voice: The photo-voice method of data collection in HIV and AIDS-related research', Journal of Psychology in Africa 18(3), 431-438.

James, A., Jenks, C. \& Prout, A., 1998, Theorising childhood, Polity Press, Cambridge.

Jensen, J.M. \& Fraser, M.W., 2005, 'A risk and resilience framework for child, youth and family policy', viewed 14 February 2013, from http://www.corwin.com/upmdata/5975_Chapter_1_Jenson_Fraser_I_Proof.pdf

Jones, N., 2008, Child protection and broader social protection linkages in West and Central Africa: Regional thematic report 5 of a study on social protection and children in West and Central Africa, Overseas Development Institute, London.

Kabiru, C.W., Izugbara, C.O. \& Beguy, D., 2013, The health and wellbeing of young people in sub-Saharan Africa: An under-researched area? viewed 10 May 2014 from http://www.biomedcentral.com/content/pdf/1472-698X-13-11.pdf

Killian, B., Van der Riet, M., O’Neill, V., Hough, A. \& Zondi, V., 2008, 'Children's loss of agency under extreme adversity', Journal of Psychology in Africa 18(3), 403-412.

Leslie, A., 2009, 'Sustainable communities: The role of global citizenship education' POLIS Journal 2, 1-44.

Lippman, L.H., Moore, K.A. \& McIntosh, H., 2009, Positive indicators of child wellbeing: A conceptual framework, measures and methodological issues, Innocenti Working Paper No. 2009-21, UNICEF Innocenti Research Centre, Florence.

Mayall, B., 2002, Towards a sociology of childhood: Thinking from children's lives, Open University Press, Buckingham.

Muthukrishna, N., 2006, Integrated report NRF Project - Mapping Barriers to Basic Education in an HIV and AIDS context, School of Education and Development, University of KwaZulu-Natal, Pietermaritzburg.

Muthukrishna, N. \& Ramsuran, A., 2007, 'Layers of oppression and exclusion in the context of HIV and AIDS: The case of adult and child learners in the Richmond district, province of KwaZulu-Natal', International Journal of Inclusive Education 11(4), 401-416. http://dx.doi.org/10.1080/13603110701391378

Muthukrishna, N., Ramsuran, A., Pennefather, J., Naidoo, J. \& Jugmohan, P., 2007 'Sense making frameworks: Dominant, discursive constructions of learners and communities by teachers in the context of intersecting barriers to basic education', communities by teachers in the context
Perspectives in Education 25(1), 31-44.

Murphy, K., 2012, 'The social pillar of sustainable development: A literature review and framework for policy analysis', Sustainability: Science, Practice \& Policy 8(1),
viewed 07 May 2013, from http://sspp.proquest.com/archives/vol8iss1/1008-041. murphy.html

Nelson Mandela Foundation, 2005, Emerging voices: A report on education in South African rural communities, HSRC Press, Cape Town.

Nkambule, T., Balfour, R., Pillay, D. \& Moletsane, R., 2011, 'Rurality and rural education: Discourses underpinning rurality and rural education research in South African postgraduate education research 1994-2004', South African Journal of Higher Education 25(2), 341-357.

Prout, A. \& James, A., 1990, 'A new paradigm for the sociology of childhood? Provenance, promise and problems', in A. James \& A. Prout (eds.), Constructing and reconstructing childhood, pp. 79-98, Falmer Press, London.
Ramsuran, A. \& Lurwengu, F., 2008, 'Relations of power in different spaces: An exploration of the schooling experiences of children in an HIV/AIDS context', Journal of Psychology in Africa 18(3), 393-402.

Republic of South Africa, 1996, South African Schools Act No. 84 of 1996, Government Press, Pretoria.

Republic of South Africa, 2005, Children's Act No. 38 of 2005, Government Press, Pretoria.

Statham, J. \& Chase, E., 2010, Childhood wellbeing: A brief overview, Childhood Wellbeing Research Centre, London, viewed January 2013, from http://www. education.gov.uk/research/data/uploadfiles/FinalChildDFEwebsite.pdf

Stevens, I. \& Hassett, P., 2007, 'Applying complexity theory to risk in child protection practice', Childhood 14(1), 128-131. http://dx.doi.org/10.1177/09075682070 72535

United Nations, 1989, UN convention of the rights of the child, UNESCO, Paris.

United Nations, 2000, United Nations millennium development goals, viewed 12 February 2011, from www.un.org/millenniumgoals

USAID, 2011, 'Children are puppets and parents move the strings', viewed 05 September 2012, from http://www.rescue.org/sites/default/files/resource-file/ IMPACT\%20Qualitative \%20Research\%20Report\%20-\%20FINAL_0.pdf

Van der Riet, M., Hough, A. \& Killian, B., 2005, 'Mapping HIV/AIDS as a barrier to education: A reflection on the methodological and ethical challenges to child participation', Journal of Education 35, 75-98.

Weingaertner, C. \& Moberg, A., 2011, 'Exploring social sustainability: Learning from perspectives on urban development and companies and products', viewed 14 July 2012, from http://doi.wiley.com/10.1002/sd.536

Willms, J.D., 2002, Vulnerable children. Findings from Canada's national longitudinal survey of children and youth, The University of Alberta Press, Alberta, Canada.

Woodcraft, S., 2011, Design for social sustainability: A framework for creating thriving communities, The Young Foundation, London.

Woodcraft, S., 2012, 'Social sustainability and new communities: Moving from concept to practice in the UK', viewed 12 February 2013, from http://social-life. $\mathrm{co} / \mathrm{media} / \mathrm{files} /$ Woodcraft_-_2012_-_Social_Sustainability_and_New_ Communities_Moving_copy.p.pdf

World Health Organization, 2007, Everybody's business: Strengthening health systems to improve health outcomes. A framework for action, World Health Organization, Geneva.

Wulczyn, F., Daro, D., Fluke, F., Feldman, S., Glodek, C. \& Lifanda, K., 2010, Adapting a systems approach to child protection: Key concepts and considerations, UNICEF, New York.

Yates, T.M. \& Masten, A.S., 2004, 'Fostering the future: Resilience theory and the practice of positive psychology', in P.A. Linley \& S. Joseph (eds.), Positive psychology in practice, Wiley, Hoboken, NJ.

Zolkoski, S.M. \& Bullock, L.M., 2012, 'Resilience in children and youth: A review', Children and Youth Services Review 34, 2295-2303. http://dx.doi.org/10.1016/j. childyouth.2012.08.009 